\title{
An analysis of crustal magnetic anomaly and Curie surface in west Himalayan syntaxis and adjacent area
}

\author{
Guoming Gao' ${ }^{1}$ Guofa Kang ${ }^{1}$ Guangquan $\mathrm{Li}^{1}$ • \\ Chunhua Bai ${ }^{1} \cdot{\text { Yingyan } \mathrm{Wu}^{2}}^{2}$
}

Received: 16 January 2016/Accepted: 6 July 2016/Published online: 15 July 2016

(C) Akadémiai Kiadó 2016

\begin{abstract}
In this paper, the magnetic model NGDC-720-V3 is used to investigate the distribution of crustal magnetic anomaly and the depth of Curie surface in west Himalayan syntaxis and its adjacent area. The Curie surface is compared with regional heat flow, the Moho, and seismicity. The results show that the magnetic anomaly and Curie surface are both consistent with the regional tectonic setting. Tarim craton, Tadjik Basin, and Indian Plate have positive magnetic anomaly and a Curie surface deeper than $36 \mathrm{~km}$, corresponding to low heat flow there. In contrast, orogenic belts such as west Himalayan syntaxis, Tianshan Mountain, Afghanistan, and Tibetan Plateau have negative anomaly and a Curie surface shallower than $32 \mathrm{~km}$, corresponding to high heat flow. The north of the syntaxis presents a positive anomaly on the surface, resulting from Ferghana Basin, while the negative anomaly in large depth is probably associated with the subduction of the slab and the resulting heat. The depth of the Curie surface has an inverse relationship to the Moho depth, which is attributed to temperature and isostatic balance. The distribution of earthquakes with epicenter deeper than $100 \mathrm{~km}$ clearly suggests the subduction of the Indian plate deep down to the asthenosphere and the deep earthquakes were caused by shear motion within the subducting slab.
\end{abstract}

Keywords West Himalayan syntaxis · Crustal magnetic anomaly $\cdot$ Curie surface $\cdot$ Spectral analysis · Isostatic balance

Guoming Gao

gmgao@ynu.edu.cn

1 Department of Geophysics, Yunnan University, 2 North Green Lake Rd., Kunming 650091, Yunnan, China

2 Institute of Earthquake Science, China Earthquake Administration, Beijing 100036, China 


\section{Introduction}

Crustal magnetic field is induced by magnetic minerals in the crust and upper mantle. Magnetic minerals provide an excellent marker for the structure and composition of the crust (Hemant and Maus 2005a, b; Aitken and Betts 2008). Thus crustal magnetic field can be used to study regional tectonics (Langel and Hinze 1998; Purucker and Whaler 2007). West Himalayan syntaxis (also called the Pamir salient) is located at the northwestern tip of the Himalayan orogen, being the frontier of the collision between the Indian and Eurasian plates (Fig. 1). As such, the syntaxis and its adjacent area are complex and interesting in geology and geophysics (Lei et al. 2002; Tiwari et al. 2009; Yang et al. 2009). Study of the crustal magnetic field in west Himalayan syntaxis $\left(65^{\circ} \mathrm{E}-80^{\circ} \mathrm{E}, 30^{\circ} \mathrm{N}-\right.$ $42^{\circ} \mathrm{N}$ ) and the topography of the magnetic layer basement, can help understand crustal structure and tectonic evolution.

Temperature is one of the most important parameters in the Earth, which contributes to the geodynamics of the lithosphere (Mayhew 1982). Considerable attention has been given to the spatial variation of temperature in lithosphere (Čermák and Bodri 1991; Seipold 1992; Artemieva and Mooney 2001). Near-surface heat flow is the primary observable quantity to determine temperature underground. However, the heat flow itself is insufficient to accurately determinate the temperature distribution over a wide region because measurement of the heat flow is often sparse and uneven (Tanaka et al. 1999). Moreover,

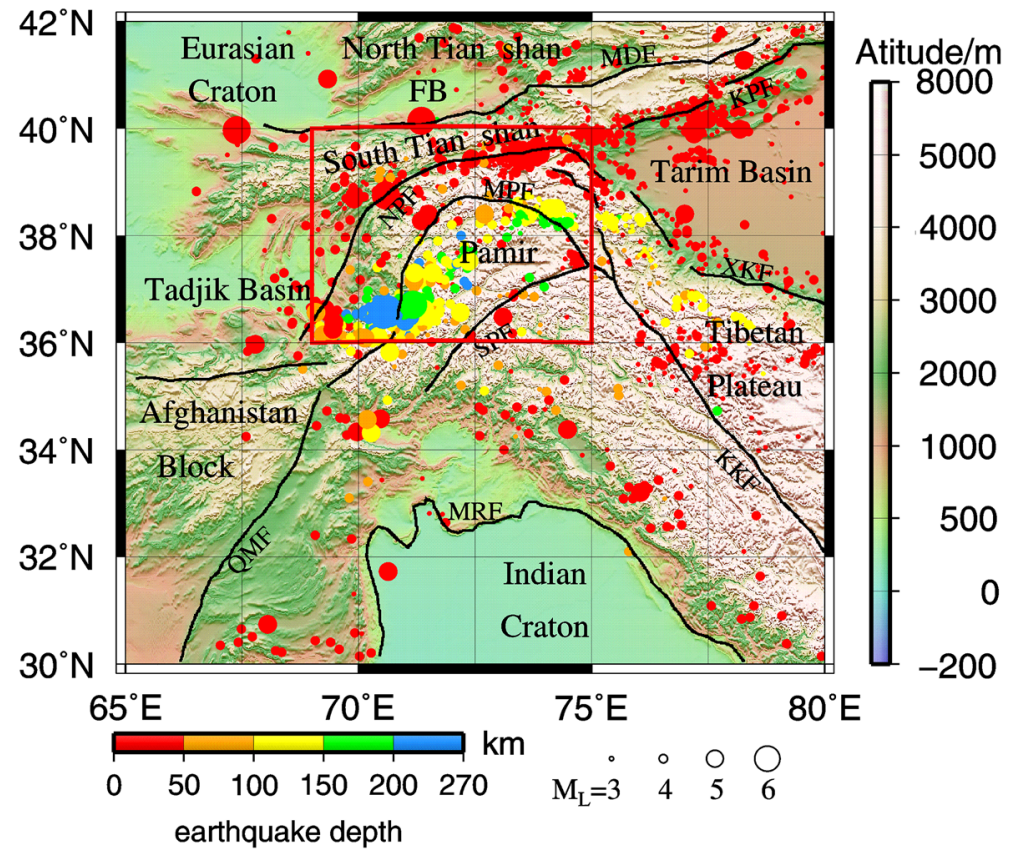

Fig. 1 Geographic map of west Himalayan syntaxis and its adjacent area, as well as regional faults and earthquakes in 2005-2015 from the China Earthquake Data Center. The red square represents the syntaxis. FB Ferghana Basin, MRT Main Boundary Fault, $Q M F$ Qia Man Fault, SPF South Pamir Fault, MPF Middle Pamir Fault, $N P F$ North Pamir Fault, $M D F$ Mai Dang Fault, $K P F$ Ke Ping Fault, $K K F$ Kaci Kunlun Fault, $X K F$ South Kunlun Fault (Colour figure online) 
we cannot directly measure the geothermal parameters at large depth. These limitations prevent us from understanding the temperature in the crust.

As an alternative, spectrum analysis of the magnetic anomaly may be used to determine the thermal state of the crust (e.g., Spector and Grant 1970). As temperature increases with depth, magnetic minerals in the lithosphere will transform from ferromagnetic state to paramagnetic (Nagata 1961), and the interface of the phase change is called Curie surface, the depth of which reflects the critical temperature (Bhattacharyya and Leu 1975b). The spectrum method has been applied to investigate the Curie surface in the USA (Mayhew 1985; Blakely 1988), in Greece (Tsokas et al. 1998; Stampolidis and Tsokas 2002), in Japan (Okubo et al. 1989; Okubo and Matsunaga 1994), in Central Europe (Chiozzi et al. 2005), in Bulgaria (Trifonova et al. 2009), in Turkey (Maden 2010; Saleh et al. 2013), and in China (Hu et al. 2006; Gao et al. 2015a, b).

In June, 2009, the National Geophysical Data Center (NGDC) of the USA established a geomagnetic field model NGDC-720-V3 by combining data from satellite, ground, oceanic and aeromagnetic surveys. In that model, the order of spherical harmonic functions is up to 720 and the resolvable spatial wavelength is as fine as $55 \mathrm{~km}$ (Maus 2010). In this paper, we are motivated to investigate the crustal magnetic anomaly in west Himalayan syntaxis and its adjacent area, using the NGDC-720-V3 model. Depth of the Curie surface is calculated through spectrum analysis of the magnetic anomaly. Finally, the Curie surface is compared with regional heat flow, the Moho, and seismicity.

\section{Tectonic setting}

As shown in Fig. 1, west Himalayan syntaxis is located in the northwestern Tibet Plateau. It connects the Himalaya with Tianshan Mountain and separates Tarim Basin from Tadjik Basin. To the south of the syntaxis is Indian Plate. To the west is Tadjik Basin floored by Triassic or Jurassic extended continental crust (Tapponnier et al. 1981; Burtman and Molnar 1993; Brookfield and Hashmat 2001). To the north is Tianshan Mountain, a complex Paleozoic accretionary orogen reactivated during the Neogene (Windley et al. 1990; Sobel et al. 2006). To the east is Tarim Basin, the basement of which is comprised of Precambrian crust.

West Himalayan syntaxis arises from the northward collision between the Indian and the Eurasian plates (Burtman and Molnar 1993; Negredo et al. 2007; Sobel et al. 2011), which is evident in the orientation of the faults there (Fig. 1). Its tectonic evolution was divided into three stages (Windley 1988; Pegler and Das 1998). At the first stage, several plates from Gondwanaland migrated northward and the Tethys gradually closed during the Mesozoic-Lower Tertiary. At the second stage, the plates accreted to the southern margin of the Eurasia, and the Indus suture zone occurred around 40-50 Ma ago. During the third stage, the post-collision indentation of Indian craton into Eurasia Plate resulted in a crustal shortening as much as $2000 \mathrm{~km}$.

West Himalayan syntaxis developed rapidly over the last $10 \mathrm{Ma}$, as Indian Plate moved northward $530 \mathrm{~km}$ relative to the Eurasia (Dewey et al. 1989). The movement displaced the earlier-formed collision mountains northward and the indenter separated the originally continuous Tadjik-Tarim Basin into two basins. West Himalayan syntaxis was a low-relief plateau on the northwest side of Karakorum-Hindu Kush mountains during the earlier Cenozoic (Ducea et al. 2003). 
The syntaxis and its surrounding area are one of the most active areas with strong seismicity (Koulakov and Sobolev 2006; Mechie et al. 2012). Figure 1 shows that in west Himalayan syntaxis, most of the earthquake occurring in 2005-2015 had epicenters deeper than $100 \mathrm{~km}$. In contrast, the surrounding area is dominated by earthquakes with epicenters shallower than $50 \mathrm{~km}$. This difference indicates that west Himalayan syntaxis may have a mechanical and/or thermal evolution different from the surrounding area.

\section{Crustal magnetic anomaly}

The crustal magnetic anomaly is generated by induced magnetization and remanent magnetization. Induced magnetization plays a main role in the crustal magnetic anomaly within the continents (Counil et al. 1991; Maus and Haak 2002), whereas remanent magnetization is the dominant cause for crustal magnetic anomaly beneath the oceans (Cohen and Achache 1994; Dyment and Arkani-Hamed 1998). Treloar et al. (1986) showed through laboratory and theoretical studies that in the lower crust, remanent magnetization is much smaller than induced magnetization.

Currently, induced and remanent magnetization in the crustal magnetic anomalies over the continents cannot be decoupled/distinguished from each other, as little is known about the structure of remanent magnetization within the continents (Hulot et al. 2009). Lesur and Gubbins (2000) attempted to use geomagnetic secular variation to separate remanent magnetization from induced magnetization, but they failed to achieve a satisfactory separation. As such, remanent magnetization is usually ignored in the continental crust (Hemant and Maus 2005a, b; Maule et al. 2005; Hemant and Mitchell 2009). Along this line, the crustal magnetic field in our study region (i.e., west Himalayan syntaxis and its adjacent area) is well assumed to be dominated by induced magnetisation.

\subsection{Calculation of crustal magnetic field}

In the spherical harmonic series of the geomagnetic field, terms with harmonic degrees $n \geq 16$ serve as the crustal magnetic field (Hemant et al. 2007; Maus et al. 2007; Purucker and Whaler 2007). For instance, the vertical component $\Delta Z$ of the crustal magnetic anomaly can be expressed as follows:

$$
\Delta Z=-\sum_{n=1}^{N} \sum_{m=0}^{n}(n+1)\left(\frac{a}{r}\right)^{n+2}\left(g_{n}^{m} \cos m \lambda+h_{n}^{m} \sin m \lambda\right) P_{n}^{m}(\cos \theta),
$$

where $r, \lambda$ and $\theta$ are radius, longitude and latitude, respectively, $a$ is the average radius of the Earth $(6371.2 \mathrm{~km}), P_{n}^{m}(\cos \theta)$ are the Schmidt quasi-normalized associated Legendre functions of degree $n$ and order $m, g_{n}^{m}$ and $h_{n}^{m}$ are spherical harmonic coefficients, and $N$ is a truncation level. Since 721-740 order coefficients of the NGNC-720-V3 model almost vanish, $N$ is set to degree 720 in this paper. Substituting the model coefficients into Eq. (1) yields the crustal magnetic anomaly on the Earth surface. With $r \geq a$, we can calculate the crustal magnetic anomaly over the ground at various altitudes. The computational grid is set to be $0.1^{\circ} \times 0.1^{\circ}$, which will facilitate the computation of derivatives. 


\subsection{Distribution of crustal magnetic anomaly}

The spatial distribution of the crustal magnetic anomaly at altitude 0,20 and $400 \mathrm{~km}$ are shown in Fig. 2. The crustal magnetic anomaly on the ground has the following characteristics. Tarim Basin, Ferghana Basin, Tadjik Basin, and Indian Plate have positive magnetic anomaly, whereas west Himalayan syntaxis, Afghanistan, and Tibet Plateau have negative anomaly.

The decay of the crustal magnetic anomaly with altitude is associated with the scale of magnetic body, the magnetism, and the burial depth. The magnetic anomaly arising from a small shallow magnetic body attenuates faster than that generated by a large deep magnetic source. With the increase of altitude, local magnetic anomaly may diminish and magnetic anomaly induced by deep larger magnetic body will become dominant.

At altitude $20 \mathrm{~km}$ (Fig. 2b), the magnetic anomalies in Afghanistan, Tianshan Mountain, and west Himalayan syntaxis decay rapidly, indicating that they originate from local shallow sources. In contrast, the positive magnetic anomalies in Tarim Basin, Indian Plate, and Tadjik Basin decay slowly, implying large deep magnetic sources there. The anomaly at altitude $400 \mathrm{~km}$ (Fig. 2c) which comes from crustal magnetic structure of long wavelength according to Hemant and Mitchell (2009), shows a distinct negative anomaly over west Himalayan syntaxis and its north, in contrast to the positive anomalies over Tarim
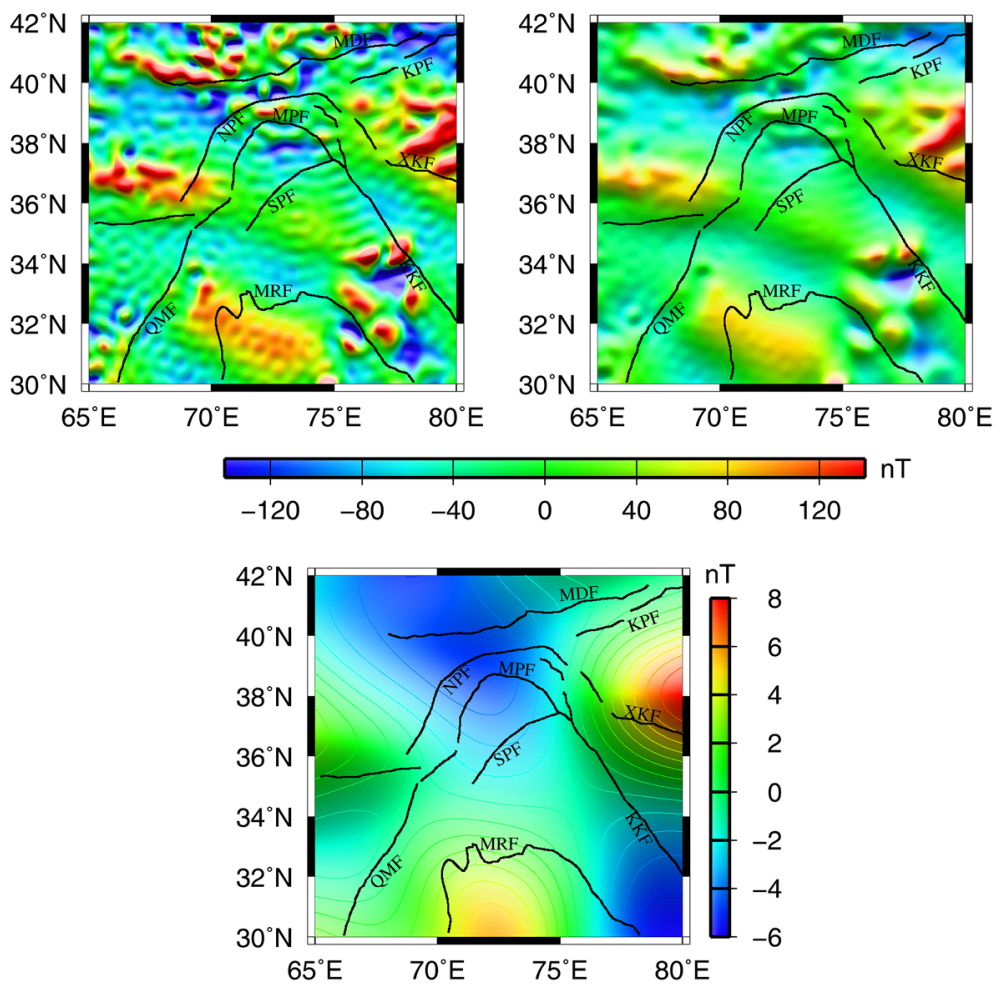

Fig. 2 Crustal magnetic anomaly over west Himalayan syntaxis and its adjacent area, with altitude at a $0 \mathrm{~km}$, b $20 \mathrm{~km}$, and c $400 \mathrm{~km}$. For abbreviations, see the caption of Fig. 1 (Colour figure online) 
craton to the east, Indian craton to the south, and Tadjik Basin to the west. We shall explain this in the Sect. 2.

\section{Curie isothermal surface}

The Curie point is approximately $580{ }^{\circ} \mathrm{C}$ for magnetite under the atmospheric pressure. Depth of the Curie point represents the depth to the bottom of magnetized rock (Lowes 2007). As the lower boundary of magnetic layer, the Curie surface has specific signature in the crustal magnetic field. Research on Curie isothermal surface could provide valuable insight in assessment of geothermal energy, calculation of thermal conductivity, as well as reconstruction of tectonic evolution. The key is how to invert for the Curie surface from the crustal magnetic anomaly.

\subsection{Calculation of the depth of Curie surface}

Crustal magnetic anomaly is a combination of the effects of shallow and deep crustal magnetic sources (Thébault et al. 2010). The Curie point depth is that of deep magnetic sources. The shallow magnetic bodies may decrease the accuracy of the Curie point depth. For this reason, the impact from shallow magnetic bodies must be removed from the magnetic anomaly. Methods of suppressing the effect of shallow magnetic source include low-pass filter (Gasparini et al. 1981), upward continuation (Guan 2005), multiscale 2D discrete wavelet analysis (Fedi and Quarta 1998; Hou and Yang 2011), and calculation of magnetic anomalies over long-to-medium wavelength bands (Hemant and Mitchell 2009; Rajaram et al. 2009; Kang et al. 2011; Gao et al. 2013), etc. In this paper, the upward continuation method is selected to eliminate influence from shallow magnetic sources. Figure $2 \mathrm{~b}$ shows that the magnetic anomaly at altitude $20 \mathrm{~km}$ above the ground has approximately removed the local features arising from shallow magnetic sources. Therefore, the magnetic anomaly at altitude $20 \mathrm{~km}$ is chosen in this paper to calculate depth of Curie surface. Such choice may influence the absolute depth of the Curie surface, but should not have a significant effect on the relative variation of the surface.

As the first order approximation, the spectra analysis method (Spector and Grant 1970; Tanaka et al. 1999; Li et al. 2010; Aboud et al. 2011) assumed that the magnetic layer extends infinitely in all horizontal directions, and thus the depth to the top of a magnetic source is negligible compared to the horizontal scale. Thus the power density spectra of a magnetic source, $P$, is (Bhattacharyya and Leu 1975a)

$$
P(|K|)=A e^{-2|K| Z_{t}}\left[1-e^{-|K|\left(Z_{b}-Z_{t}\right)}\right]^{2},
$$

where $A$ is a constant, $Z_{t}$ and $Z_{b}$ are the depth to the top and the depth to the bottom of the magnetic source, respectively, and $K$ is the wavenumber from the 2D Fourier expansion of the magnetic anomaly field. For wavelengths smaller than twice of the thickness of the magnetic layer, Eq. (2) simplifies to:

$$
\ln \left[P(|K|)^{1 / 2}\right]=\ln B-|K| Z_{t}
$$

where $B$ is a constant. Equation (3) provides an approach to estimate $\mathrm{Z}_{\mathrm{t}}$. On the other hand, Eq. (2) can be rearranged as: 


$$
P(|K|)^{1 / 2}=C e^{-|K| Z_{0}}\left[e^{-|K|\left(Z_{t}-Z_{0}\right)}-e^{-|K|\left(Z_{b}-Z_{0}\right)}\right]
$$

where $C$ is a constant, and $Z_{0}$ is the depth to the centre of the magnetic source. At long wavelength, Eq. (4) may be rewritten as:

$$
P(|K|)^{1 / 2}=C e^{-|K| Z_{0}}\left(e^{-|K|(-d)}-e^{-|K|(d)}\right) \approx C e^{-|K| Z_{0}} 2|K| d
$$

where $2 d$ is the thickness of the magnetic source. Thus for long wavelengths, we have (Tanaka et al. 1999)

$$
\ln \left[P(|K|)^{1 / 2} /|K|\right]=\ln D-|K| Z_{0}
$$

where $D$ is a constant.

By fitting a straight line through the high wavenumbers of the spectrum of $\ln \left[P(|K|)^{1 / 2}\right]$ via (3) and a straight line through the low wavenumbers of the spectrum of $\ln \left\{\left[P(|K|)^{1 / 2}\right] /\right.$ $|K|\}$ via (5), $Z_{t}$ and $Z_{0}$ can be calculated, respectively. Note that the depth to the bottom of the magnetic source is:

$$
Z_{b}=2 Z_{0}-Z_{t}
$$

In the procedure of calculation of the Curie depth, we first divide the study region into a grid of $23 \times 22$ squares, each having a size of $150 \mathrm{~km} \times 150 \mathrm{~km}$. Such grid is appropriate, as the square area must be at least four or six times the depth of the magnetic source (Dimitriadis et al. 1987; Nwobgo 1998). Two neighboring squares have an overlap of $50 \%$. Second, we calculate $\ln \left[P(|K|)^{1 / 2}\right]$ and $\ln \left\{\left[P(|K|)^{1 / 2}\right] /|K|\right\}$ for each square. Third, we select the amplitude spectra in frequency interval $0.275-0.649 \mathrm{rad} / \mathrm{km}$ (the medium-tohigh wavenumber domain) to fit $Z_{\mathrm{t}}$ via Eq. (3). We have arrived at the frequency limits after several trials. A higher frequency would lead to detection of small magnetic sources in the subsurface (Fig. 3a), but the small sources would invalidate the assumption of a horizontal scale much larger than the depth, or the applicability of Eq. (3). The ratio of amplitude spectrum to wavenumber in frequency interval $0.099-0.255 \mathrm{rad} / \mathrm{km}$ (the low
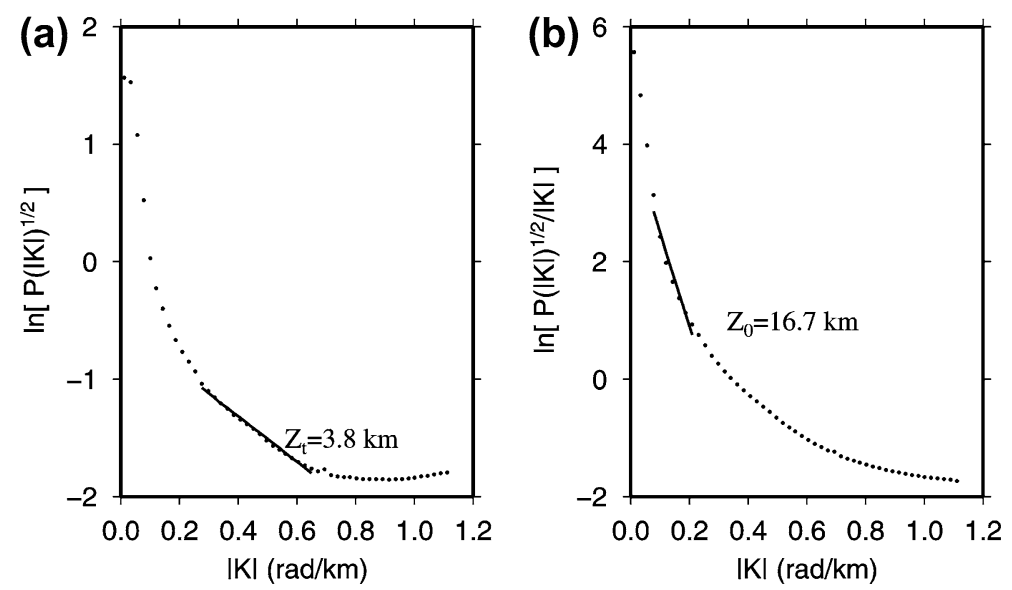

Fig. 3 Power spectrum analysis for a subregion to calculate $\mathbf{a} Z_{\mathbf{t}}$ and $\mathbf{b} Z_{0}$ through linear regression (Colour figure online) 
wavenumber domain) is used to fit $Z_{0}$ via (6). Finally, the depth to Curie surface is got via (7). In Fig. 3, an example of the power spectrum fitting in a subregion is illustrated. The centroid depth $Z_{0}$ is $16.7 \mathrm{~km}$, the depth to the top $Z_{t}$ is $3.8 \mathrm{~km}$, and the Curie point depth is $25.8 \mathrm{~km}$ for the subregion.

After getting the depths to the Curie surface for each square, we use a minimum curvature method to interpolate the depths of Curie surface for the whole study region. Figure 4 shows the distribution of the depth to the Curie surface. The result shows that the Curie surface in west Himalayan syntaxis and its adjacent area varies significantly in depth, ranging from 20 to $44 \mathrm{~km}$ with an average $30 \mathrm{~km}$.

\subsection{Curie surface}

The variation of the Curie surface in Fig. 4 correlates well with the distribution of the crustal magnetic anomaly at altitude $20 \mathrm{~km}$ (Fig. 2b). This is because a deep magnetic source will tend to generate positive magnetic anomaly, and vice versa. According to Fig. 4, the smallest feature of the Curie surface has a horizontal scale of about $100 \mathrm{~km}$, much larger than the largest depth $44 \mathrm{~km}$, and therefore, the assumption that the magnetic layer extends infinitely in all horizontal directions is approximately satisfied.

As an orogenic belt, west Himalayan syntaxis is dominated by shallow Curie surface, which is consistent with the negative anomaly there. To the southwest of the syntaxis, Afghanistan and to the southeast, Tibet has negative magnetic anomaly, well corresponding to a shallow Curie surface. The depth of the Curie surface in these orogenic belts ranges from 20 to $32 \mathrm{~km}$.

To the east of west Himalayan syntaxis, Tarim craton has a deep Curie surface and positive magnetic anomaly. To the south of the syntaxis, Indian Plate has a deep Curie

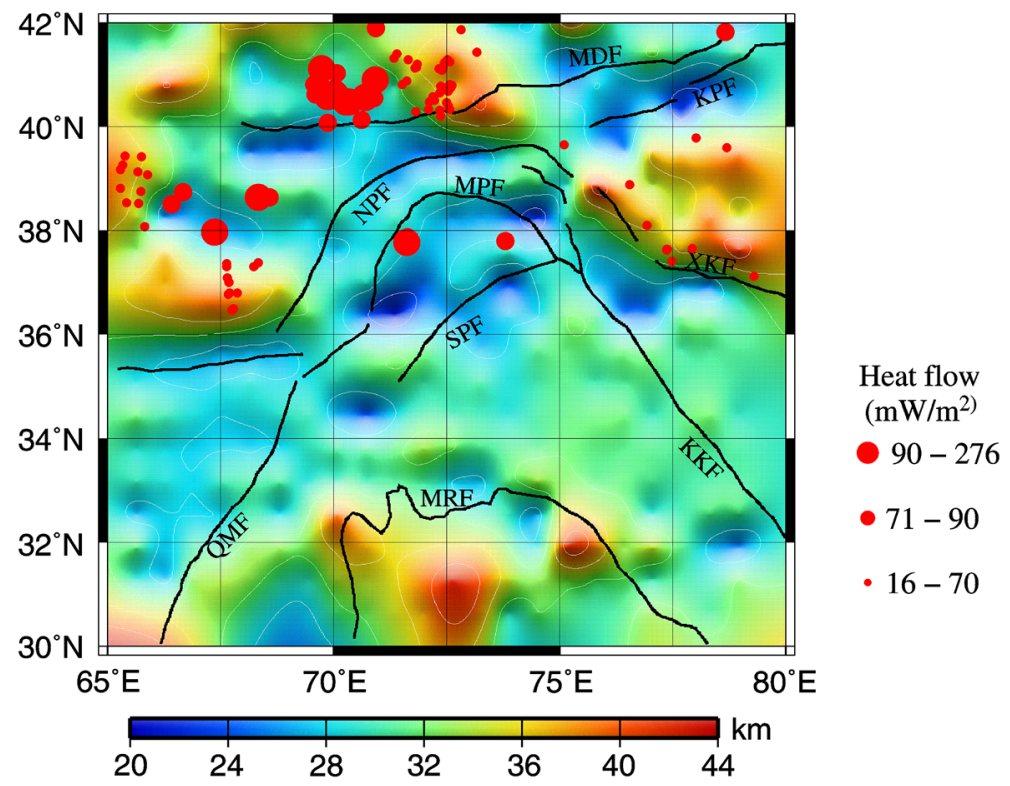

Fig. 4 Depth of the Curie surface in west Himalayan syntaxis and its surrounding area, as well as value of the heat flow (Colour figure online) 
surface and positive anomaly. To the west of the syntaxis, Tadjik Basin has a deep Curie surface and positive magnetic anomaly. The deepest Curie surface in Tarim craton is $42 \mathrm{~km}$, the deepest surface in Indian craton is $44 \mathrm{~km}$, and that in Tadjik craton is $41 \mathrm{~km}$.

The heat flow data in the study region are acquired from the Global Heat Flow Database of the International Heat Flow Commission (http://www.heatflow.und.edu/data.html), being listed in Fig. 4. It can be seen that low heat flow is located near Tarim Basin, Tadjik Basin, east part of Fergana Basin, with a value of $16-70 \mathrm{~mW} / \mathrm{m}^{2}$, corresponding to a deep Curie surface. High heat flow occurs in west Himalayan syntaxis, south Tianshan Mountain, and west of Fergana Basin, reaching more than $70 \mathrm{~mW} / \mathrm{m}^{2}$ and corresponding to a shallow Curie surface.

To compare the Curie surface with the Moho discontinuity (Moho), we invert for the Moho using the Parker-Oldenburg method (Gómez-Ortiz and Agarwal 2005) based on the Bouguer gravity anomalies, which derived from the World gravity model WGM2012 (Bonvalot et al. 2012). To remove the very details in the final map, low-pass filtering of the Bouguer anomalies was conducted using the 2D seven-point smoothing method (Liu 2004). We adopt a constant density contrast of $0.5 \mathrm{~g} / \mathrm{cm}^{3}$ (Rabbel et al. 2013) to estimate the Moho depths (Fig. 5). As shown in Fig. 5, the Moho depth and the Curie surface present roughly an inverse correspondence. In west Himalayan syntaxis, south Tianshan Mountain, Afghanistan, and Tibetan Plateau, the Moho is deep but the Curie surface is shallow. In Tarim Basin, Tadjik Basin, and Indian Plate, the situation is in reverse, and the Curie surface and Moho also present an inverse correspondence in depth.

The depths of the Curie surface and the Moho are close in Tarim Basin and Tadjik Basin, such that the Moho could be considered as a magnetic boundary. Above is the magnetic crust, while below is the nonmagnetic upper mantle. In north Indian Plate, the depth of the Curie surface is larger than that of the Moho, indicating that the upper mantle there is magnetic. South Tianshan Mountain, west Himalayan syntaxis, Afghanistan, and

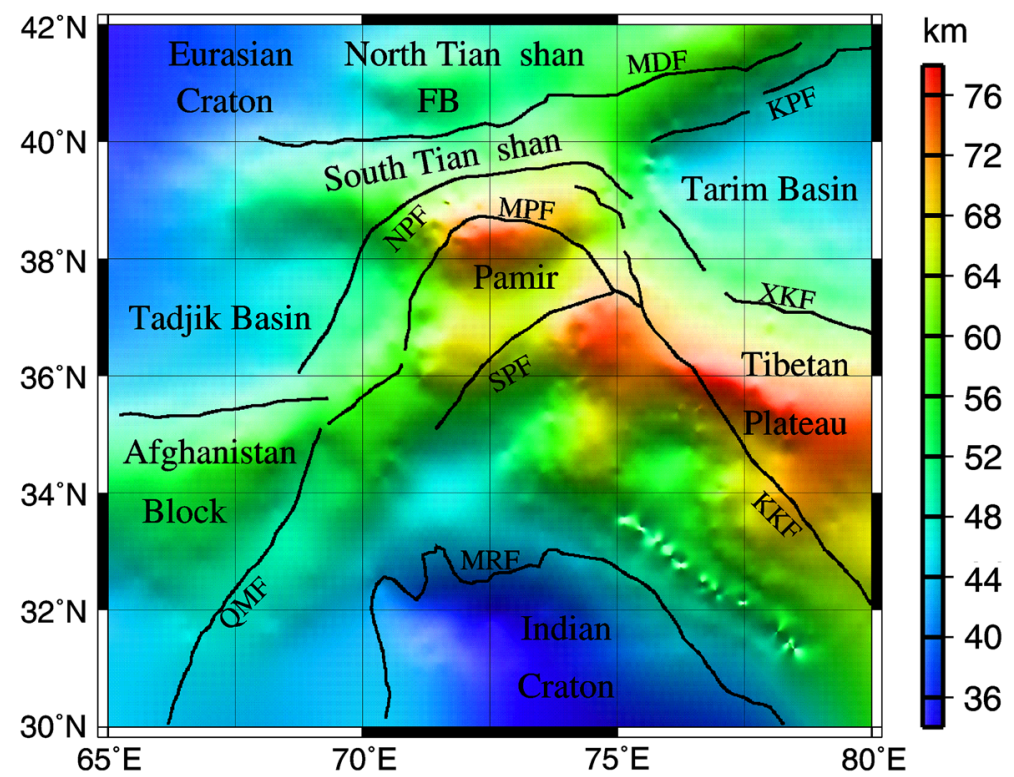

Fig. 5 Depth of the Moho under west Himalayan syntaxis (Colour figure online) 
Tibetan Plateau are Cenozoic orogenic belts, where the depth of Curie surface is less than $32 \mathrm{~km}$ but the Moho is deeper than $60 \mathrm{~km}$.

Such inverse correlation between the depth of the Curie surface and that of the Moho may be attributed to temperature: An orogenic belt has high temperature which facilitates the formation of folds. Because the elevation of an orogenic belt is higher than that of the basin, the Moho beneath the orogenic belt must be deeper than that under the basin, to achieve isostatic balance (Sleep and Fujita 1997). This is essentially the Airy-Heiskanen isostatic model, which is based on mechanical considerations. The orogenic belt is more or less similar to a low density wood floating on the surface of water (analogous to the mantle). Because the density difference between an orogenic belt and the air is much larger than that between the orogenic belt and the mantle, the depth difference in Moho between the orogenic belt and the basin must be much larger than the elevation difference between them. This is confirmed by the fact that in Fig. 1, the elevation difference between mountain and basin is about $4000 \mathrm{~m}$, while the depth difference in Moho is about $30 \mathrm{~km}$. The higher temperature in the orogenic belts associated with the deeper Moho results in, on the other hand, a shallow Curie surface, such that the Moho and the Curie surface are inversely correlated in depth.

\section{Discussion}

For comparing the seismicity and the thermal state of the study area, we plot the epicenters with magnitude larger than Ms 3.0 occurred from 2005 to 2015 in Fig. 1. The seismic data are from the China Earthquake Data Center catalogues. The seismicity is distributed along the fault zones. Comparing Fig. 4 with Fig. 1, it is found that most of the earthquakes occur where the Curie surface is shallow. The probable mechanism is that generally at where the Curie surface is shallow, the hot mantle materials are upwelling and the upward movement tends to trigger earthquakes. An exception is that along the MPF (in Pamir) in Fig. 1 are distributed with many earthquakes deeper than $100 \mathrm{~km}$ but this area has shallow Curie surface implying hot crust. The reason is the subduction of the Hindu Kush slab from the south deep into the asthenosphere underlying the hot Pamir (Negredo et al. 2007). Actually, the distribution of earthquakes with epicenter deeper than $100 \mathrm{~km}$ (in Fig. 1) clearly suggests the subduction of the Indian plate deep down to the asthenosphere and the deep earthquakes were probably caused by shear motion within the subducting slab.

The orientation of faults and geological structures in west Himalayan syntaxis and the adjacent area, as shown in Fig. 1, indicates that as Indian Plate moves northward, It is blocked by the rigid Tarim Basin on the east and the rigid Tadjik Basin on the west, such that the crustal material wedged northward between these two basins, as shown in Fig. 2c.

According to Fig. 2a, the north side of west Himalayan syntaxis has strong positive magnetic anomaly. However, Fig. 2c shows that in the deep, west Himalayan syntaxis and its north is dominated by negative crustal magnetic anomaly. It is because this area is occupied by the Ferghana basin characterized by positive anomaly.

According to Fig. 2c, west Himalayan syntaxis and its north have strong negative anomaly in the depth, but to the east of the syntaxis (Tarim craton), to the west (Tadjik basin), and to the south (Indian craton), have positive anomaly. This framework may be caused by northward subduction of Indian craton beneath Eurasian Plate (Kind et al. 2002). The subduction caused melting of the slab and upwelling of heat, such that there is no 
magnetism in the deep lithosphere under the syntaxis and the Curie surface appears to be uplifted.

The Curie surface in north Tianshan Mountain is as deep as $39 \mathrm{~km}$, while that in south Tianshan Mountain is as low as $25 \mathrm{~km}$ (Fig. 4), which implies different thermal evolution histories between them. Study of the seismic wave velocity structure (e.g., Lei et al. 2002) showed that in south Tianshan Mountain, the shallow and low velocity sediments to the south probably underthrusted into the deep crust, producing heat by friction and leading to a shallow Curie surface than that under north Tianshan Mountain.

West Himalayan syntaxis and Tibet Plateau both formed as a result of the close of the Tethys ocean (Pegler and Das 1998). Nonetheless, west Himalayan syntaxis is the frontier of the collision between the Indian and the Eurasian plate. Figure 1 shows that the earthquakes in west Himalayan syntaxis are stronger and more frequent than those in Tibetan Plateau during the period from 2005 to 2015. Thus west Himalayan syntaxis is characterized by more active tectonics than Tibet Plateau. Figure 4 also shows that the Curie surface in west Himalayan syntaxis is shallower than that in Tibetan Plateau, indicating a hotter crust than that in Tibetan Plateau.

\section{Conclusions}

The magnetic anomaly in west Himalayan syntaxis and the surrounding area well reflected the regional tectonic structure. The orogenic belts such as west Himalayan syntaxis, Tianshan Mountain, Afghanistan, and Tibetan Plateau have negative anomaly, whereas Tarim craton, Indian Plate, and Tadjik Basin have positive magnetic anomaly. The north of the syntaxis presents a positive anomaly on the surface, resulting from Ferghana Basin, while in the depth the negative anomaly is probably associated with the subduction of the slab and the resulting heat.

The depth of the Curie surface was calculated by the upward continuation of the magnetic anomaly field and linear regression of the power spectra. The topography of the Curie surface appears to be consistent with the crustal magnetic anomaly and the tectonic setting. Shallow Curie surface well corresponds to negative anomaly found along orogenic belts, while deep Curie surface is associated with positive magnetic anomaly and resides in cratons or basins. The Curie surface is roughly consistent with the observed heat flow, i.e., high heat flow occurs where the Curie surface is shallow, while low heat flow occurs where the Curie surface is deep.

The Curie surface and the Moho present an inverse correspondence in depth. In west Himalayan syntaxis, Tianshan Mountain, Afghanistan, and Tibetan Plateau, the Curie surface is shallow where the Moho is deep. In Tarim Basin, Tadjik Basin, and Indian Plate, the Curie surface is deep where the Moho is shallow. Such correlation is attributed to isostatic balance. On the other hand, the orogenic belt in the study area is characterized by elevated subsurface temperature resulting in shallow Curie surface beneath the belt.

Many earthquakes deeper than $100 \mathrm{~km}$ are distributed along the MPF (in Pamir) where the Curie surface appears to be shallow, implying hot crust. Such a distribution evidently indicates the subduction of the Hindu Kush slab from the south deep down to the asthenosphere underlying the Pamir. The deep earthquakes were likely to be induced by shear motion within the subduction slab.

Acknowledgments This study was sponsored by the National Science Foundation of China under Grant 41404055, Grant 41264003 and Grant 41304054, Yunnan Applied Basic Research Project under contract 
2014FB107, and the State Administration of Science Technology and Industry for National Defense Project under Grant ZH-1-DMYZ-01-04. We are grateful anonymous reviewers for their insightful comments and contributing suggestions.

\section{References}

Aboud E, Salem A, Mekkawi M (2011) Curie depth map for Sinai Peninsula, Egypt deduced from the analysis of magnetic data. Tectonophysics 506:46-54. doi:10.1016/j.tecto.2011.04.010

Aitken ARA, Betts PG (2008) High-resolution aeromagnetic data over central Australia assist Grenville-era (1300-1100 Ma) Rodinia reconstructions. Geophys Res Lett. doi:10.1029/2007GL031563

Artemieva IM, Mooney WD (2001) Thermal thickness and evolution of Precambrian lithosphere: a global study. J Geophys Res 106:16387-16414

Bhattacharyya BK, Leu LK (1975a) Spectral analysis of gravity and magnetic anomalies due to twodimensional structures. Geophysics 40:993-1013. doi:10.1190/1.1440593

Bhattacharyya BK, Leu LK (1975b) Analysis of magnetic anomalies over Yellowstone National Park: mapping of Curie point isothermal surface for geothermal reconnaissance. J Geophys Res $80: 4461-4465$

Blakely RJ (1988) Curie temperature analysis and tectonic implications of aeromagnetic data from Nevada. J Geophys Res 93:11817-11832

Bonvalot S, Balmino G, Briais A, Kuhn M, Peyrefitte A, Vales N, Biancale R, Gabalda G, Reinquin F, Sarrailh M (2012) World Gravity Map. Commission for the Geological Map of the World. Eds. BGICGMW-CNES-IRD, Paris

Brookfield ME, Hashmat A (2001) The geology and petroleum potential of the North Afghan platform and adjacent areas (northern Afghanistan, with parts of southern Turkmenistan, Uzbekistan and Tajikistan). Earth-Sci Rev 55:41-71

Burtman VS, Molnar P (1993) Geological and geophysical evidence for deep subduction of continental crust beneath the Pamir. GSA Spec Pap 281:1-76

Čermák V, Bodri L (1991) A heat production model of the crust and upper mantle. Tectonophysics 194:307-323. doi:10.1016/0040-1951(91)90300-H

Chiozzi P, Matsushima J, Okubo Y, Pasquale V, Verdoya M (2005) Curie point depth from spectral analysis of magnetic data in central-southern Europe. Phys Earth Planet Inter 152:267-276

Cohen Y, Achache J (1994) Contribution of induced and remanent magnetization to long-wavelength oceanic magnetic anomalies. J Geophys Res 99:2943-2954

Counil J, Cohen Y, Achache J (1991) The global continent-ocean magnetization contrast. Earth planet Sci Lett 103:354-364

Dewey JF, Cande S, Pitman WC (1989) The tectonic evolution of the India/Eurasia collision zone. Eclogae Geol Helv 82:717-734

Dimitriadis K, Tselentis GA, Thanassoulas K (1987) A basic program for 2-D spectral analysis of gravity data and source-depth estimation. Comput Geosci 13:549-560

Ducea MN, Lutkov V, Minaev VT, Hacker B, Ratschbacher L, Luffi P, Schwab M, Gehrels GE, McWilliams M, Vervoort J, Metcalf J (2003) Building the Pamirs: the view from the underside. Geology 31:849-852

Dyment J, Arkani-Hamed J (1998) Contribution of lithospheric remanent magnetization to satellite magnetic anomalies over the world's oceans. J Geophys Res 103:15423-15441

Fedi M, Quarta T (1998) Wavelet analysis for the regional residual and local separation of potential field anomalies. Geophys Prospect 46:507-525

Gao G, Kang G, Bai C, Li G (2013) Distribution of the crustal magnetic anomaly and geological structure in Xinjiang, China. J Asian Earth Sci 77:12-20.doi:10.1016/j.jseaes.2013.08.014

Gao G, Kang G, Bai C, Wen L (2015a) Study on crustal magnetic anomalies and Curie surface in Southeast Tibet. J Asian Earth Sci 97:169-177. doi:10.1016/j.jseaes.2014.10.035

Gao G, Kang G, Li G, Bai C (2015b) Crustal magnetic anomaly and Curie surface beneath Tarim Basin, China, and its adjacent area. Can J Earth Sci 52:357-367. doi:10.1139/cjes-2014-0204

Gasparini P, Mantovani MSM, Shukowsky W (1981) On the possibility of a direct automatic inversion of the D.C. geoelectric data. In: Cassinis R (ed) The solution of the inverse problem in geophysical interpretation. Plenum Press, New York, pp 112-124

Gómez-Ortiz D, Agarwal BNP (2005) 3DINVER.M: a MATLAB program to invert the gravity anomaly over a 3D horizontal density interface by Parker-Oldenburg's algorithm. Comput Geosci 31:513-520 
Guan ZN (2005) Geomagnetic field and magnetic exploration. Geological Publishing House, Beijing (in Chinese)

Hemant K, Maus S (2005a) Geological modeling of the new CHAMP magnetic anomaly maps using a geographical information system (GIS) technique. J Geophys Res. doi:10.1029/2005JB003837

Hemant K, Maus S (2005b) Why no anomaly is visible over most of the continent-ocean boundary in the global crustal magnetic field. Phys Earth Planet Inter 149:321-333

Hemant K, Mitchell A (2009) Magnetic field modeling and interpretation of the Himalayan-Tibetan Plateau and adjoining north Indian Plains. Tectonophysics 487:87-99

Hemant K, Thébault E, Mandea M, Ravat D, Maus S (2007) Magnetic anomaly map of the world: merging satellite, airborne, marine and ground-based magnetic data sets. Earth Planet Sci Lett 260:56-71

Hou Z, Yang W (2011) Multi-scale inversion of density structure from gravity anomalies in Tarim Basin. Sci China Earth Sci 54:399-409

Hu X, Xu M, Xie X, Wang L, Zhang Q, Liu S, Xie G, Feng C (2006) A characteristic analysis of aeromagnetic anomalies and Curie point isotherms in Northeast China. Chin J Geophys 49:1674-1681

Hulot G, Olsen N, Thébault E, Hemant K (2009) Crustal concealing of small-scale core-field secular variation. Geophys J Int 177:361-366

Kang G, Gao G, Bai C, Shao D, Feng L (2011) Characteristics of the crustal magnetic anomaly and regional tectonics in the Qinghai-Tibet Plateau and the adjacent areas. Sci China Earth Sci 6:1028-1036

Kind R, Yuan X, Saul J, Nelson D, Sobolev SV, Mechie J, Zhao W, Kosarev G, Ni J, Achauer U, Jiang M (2002) Seismic images of crust and upper mantle beneath Tibet: evidence for Eurasian Plate subduction. Science 298:1219-1221

Koulakov I, Sobolev SV (2006) A tomographic image of Indian lithosphere break-off beneath the PamirHindukush region. Geophys J Int 164:425-440

Langel RA, Hinze WJ (1998) The magnetic field of the earth's lithosphere: the satellite perspective. Cambridge University Press, Cambridge

Lei J, Zhou H, Zhao D (2002) 3-D velocity structure of P-wave in the crust and upper-mantle beneath Pamir and adjacent region. Chin J Geophys 45:802-811

Lesur V, Gubbins D (2000) Using geomagnetic secular variation to separate remanent and induced sources of the crustal magnetic field. Geophys J Int 142:889-897

Li C, Shi X, Zhou Z, Li J, Geng J, Chen B (2010) Depths to the magnetic layer bottom in the South China Sea area and their tectonic implications. Geophys J Int 182:1229-1247. doi:10.1111/j.1365-246X. 2010.04702.x

Liu T (2004) Application of geophysical data acquisition and processing. China University of Geosciences Press, Wuhan, pp 4-7 (in Chinese)

Lowes F (2007) Geomagnetics spectrum, spatial. In: Gubbins D, Herrero-Bervera E (eds) Encyclopedia of geomagnetism and paleomagnetism. Springer, Berlin, pp 350-353

Maden N (2010) Curie-point depth from spectral analysis of magnetic data in Erciyes Stratovolcano (Central TURKEY). Pure appl Geophys 167:349-358

Maule CF, Purucker ME, Olsen N, Mosegaard K (2005) Heat flux anomalies in Antarctica revealed by satellite magnetic data. Science 309:464-467

Maus S (2010) An ellipsoidal harmonic representation of Earth's lithospheric magnetic field to degree and order 720. Geochem Geophys Geosyst 11:06015. doi:10.1029/2010GC003026

Maus S, Haak V (2002) Is the long wavelength crustal magnetic field dominated by induced or by remanent magnetisation? J Indian Geophys Union 6:1-5

Maus S, Sazonova T, Hemant K, Fairhead JD, Dhananjay R (2007) National geophysical data centers candidate for the world digital magnetic anomaly map. Geochem Geophys Geosyst 8:Q06017

Mayhew MA (1982) Application of satellite magnetic anomaly data to Curie isotherm mapping. J Geophys Res 87:4846-4854

Mayhew MA (1985) Curie isotherm surfaces inferred from high-altitude magnetic anomaly data. J Geophys Res 90:2647-2654

Mechie J, Yuan X, Schurr B, Schneider F, Sippl C, Ratschbacher L, Minaev V, Gadoev M, Oimahmadov I, Abdybachaev U, Moldobekov B, Orunbaev S, Negmatullaev S (2012) Crustal and uppermost mantle velocity structure along a profile across the Pamir and southern Tien Shan as derived from project TIPAGE wide-angle seismic data. Geophys J Int 188:385-407

Nagata T (1961) Rock magnetism. Maruzen, Tokyo

Negredo AM, Replumaz A, Villaseñor A, Guillot S (2007) Modeling the evolution of continental subduction processes in the Pamir-Hindu Kush region. Earth Planet Sci Lett 259:212-225. doi:10.1016/j.epsl. 2007.04.043

Nwobgo PO (1998) Spectral prediction of magnetic source depths from simple numerical models. Comput Geosci 24:847-852 
Okubo Y, Matsunaga T (1994) Curie point depth in northeast Japan and its correlation with regional thermal structure and seismicity. J Geophys Res 99:22363-22371

Okubo Y, Tsu H, Ogawa K (1989) Estimation of Curie point temperature and geothermal structure of island arcs of Japan. Tectonophysics 159:279-290

Pegler G, Das S (1998) An enhanced image of the Pamir-Hindu Kush seismic zone from relocated earthquake hypocenters. Geophys J Int 134:573-595

Purucker ME, Whaler KA (2007) Crustal magnetization. Treatise Geophys 5:195-235

Rabbel W, Kaban M, Tesauro M (2013) Contrasts of seismic velocity, density and strength across the Moho. Tectonophysics 609:437-455

Rajaram M, Anand SP, Hemant K, Purucker ME (2009) Curie isotherm map of Indian subcontinent from satellite and aeromagnetic data. Earth Planet Sci Lett 281:147-158

Saleh S, Salk M, Pamukcu O (2013) Estimating Curie point depth and heat flow map for northern Red Sea Rift of Egypt and its surroundings from aeromagnetic data. Pure appl Geophys 170:863-885

Seipold U (1992) Depth dependence of thermal transport properties for typical crustal rocks. Phys Earth Planet Inter 69:299-303

Sleep NH, Fujita K (1997) Principles of Geophysics. Blackwell

Sobel ER, Chen J, Heermance RV (2006) Late Oligocene-Early Miocene initiation of shortening in the Southwestern Chinese Tian Shan: implications for Neogene shortening rate variations. Earth Planet Sci Lett 247:70-81. doi:10.1016/j.eps1.2006.03.048

Sobel ER, Schoenbohm LM, Chen J, Thiede R, Stockli DF, Sudo M, Strecker MR (2011) Late MiocenePliocene deceleration of dextral slip between Pamir and Tarim: implications for Pamir orogenesis. Earth Planet Sci Lett 304:369-378. doi:10.1016/j.eps1.2011.02.012

Spector A, Grant FS (1970) Statistical models for interpreting aeromagnetic data. Geophysics 35:293-302

Stampolidis A, Tsokas G (2002) Curie point depths of Macedonia and Thrace, N. Greece. Pure appl Geophys 159:1-13

Tanaka A, Okubo Y, Matsubayashi O (1999) Curie point depth based on spectrum analysis of the magnetic anomaly data in East and Southeast Asia. Tectonophysics 306:461-470

Tapponnier P, Mattauer M, Proust F, Cassaigneau C (1981) Mesozoic ophiolites, sutures, and arge-scale tectonic movements in Afghanistan. Earth Planet Sci Lett 52:355-371

Thébault E, Purucker M, Whaler KA, Langlais B, Sabaka TJ (2010) The magnetic field of the earth's lithosphere. Space Sci Rev 155:95-127

Tiwari VM, Rajasekhar RP, Mishra DC (2009) Gravity anomaly, lithospheric structure and seismicity of west Himalayan syntaxis. J. Seismol. 13:363-370

Treloar NA, Shive PN, Fountain DM (1986) Viscous remanence acquisition in deep crustal rocks (abstract). EOS Trans AGU 67:266

Trifonova P, Zhelev Z, Petrova T, Bojadgieva K (2009) Curie point depths of Bulgarian territory inferred from geomagnetic observations and its correlation with regional thermal structure and seismicity. Tectonophysics 473:362-374

Tsokas G, Hansen RO, Fyticas M (1998) Curie point depth of the Island of Crete (Greece). Pure appl Geophys 152:747-757

Windley BF (1988) Tectonic framework of the Himalaya, Karakoram and Tibet, and problems of their evolution. Phil Trans R Soc Lond A326:3-16

Windley BF, Allen MB, Zhang C, Zhao Z, Wang G (1990) Paleozoic accretion and Cenozoic redeformation of the Chinese Tien Shan Range, central Asia. Geology 18:128-131. doi:10.1130/0091-7613

Yang H, Teng J, Zhang X, Sun R, Ke X (2009) Features of the deep geophysical field beneath the west Himalayan syntaxis. Progr Geophys 24:1975-1986. doi:10.3969/j.issn.1004-2903.2009.06.007 